\title{
Oceanic circulation, local upwelling and palaeoclimatic changes linked to the phylogeography of the Cape sea urchin Parechinus angulosus
}

\author{
Cornelius M. Muller ${ }^{1}$, Sophie von der Heyden ${ }^{1}$, Rauri C. K. Bowie ${ }^{2}$, \\ Conrad A. Matthee ${ }^{1, *}$ \\ ${ }^{1}$ Evolutionary Genomics Group, Department of Botany and Zoology, University of Stellenbosch, Private Bag X1, Matieland, \\ Stellenbosch, 7602, South Africa \\ ${ }^{2}$ Museum of Vertebrate Zoology and Department of Integrative Biology, 3101 Valley Life Science Building, \\ University of California, Berkeley, California 94720, USA
}

\begin{abstract}
To enhance our current understanding of the evolution of intertidal marine species, we investigated the phylogeographic population structure of the Cape sea urchin Parechinus angulosus using cytochrome c oxidase subunit I (COI) mitochondrial and receptor for egg jelly protein 9 (SpREJ9) nuclear DNA (nDNA) sequence data. The species shows variation in colour form, has a wide distribution along the southern African coastline, a broadcast mode of reproduction and probably a fairly long post larval development. Despite the prediction that species with such life history traits will show shallow genetic differentiation among sampling sites, high levels of population differentiation were obtained among many of the 18 sampling localities. The trend was particularly strong along the west coast Namaqua biogeographic province of southern Africa where the structure was also correlated with local upwelling. Larval dispersal broadly corresponded with oceanic currents and 2 distinct geographic genetic groupings were detected. The first grouping represents most individuals sampled along the cool temperate west coast, while the second comprises individuals sampled from the south and east coasts of southern Africa. The genetic separation of $P$. angulosus individuals is in the vicinity of a recognized biogeographic barrier (Cape Point), and is supported by geneflow analyses, parsimony haplotype networks for both nDNA and mtDNA data, and a mtDNA Bayesian analyses of population structure. Expansion events for the Cape sea urchin, and the divergence time estimates between the 2 assemblages, centre around the last glacial maximum and provide substantial support that glaciations and associated lowering and rising of sea levels significantly affected marine rocky shore organisms along the southern African coastline.
\end{abstract}

KEY WORDS: Southern Africa $\cdot$ Echinodermata $\cdot$ Phylogeography $\cdot$ Geneflow $\cdot$ Sea-level change SpREJ $\cdot$ mtDNA COI

Resale or republication not permitted without written consent of the publisher

\section{INTRODUCTION}

Understanding population connectivity and geneflow in the marine environment is critical for informing conservation strategies related to the establishment of marine protected areas and other conservation measures (Kelly \& Palumbi 2010 and references therein, Waters et al. 2010). Recent regional phylogeographic reviews comparing a large number of marine faunal lineages support the hypothesis that biogeographic barriers, together with life history traits, play an important role in speciesspecific geneflow patterns (e.g. Ross et al. 2009, Kelly \& Palumbi 2010, Sivasundar \& Palumbi 2010). It is 
clear from these studies that connectivity at the regional scale is the result of interactions between life history (including larval behaviour), ocean currents, upwelling, population identity, and habitat availability (Avise 1992, Sherman et al. 2008). For example, it has been suggested that weak upwelling contributes to high levels of larval settlement while strong upwelling may limit larval settlement (Sivasundar \& Palumbi 2010). However, the effect of upwelling is also dependent on larval behaviour and factors such as different pelagic larval duration times among species (Ross et al. 2009). Importantly, seasonal shifts in currents and upwelling, coupled to the timing of reproduction, can also have significant consequences for the transport and recruitment success of immature stages (Largier 2004, Levin 2006).

The southern African coastline has several unique features that can potentially influence the dispersal and successful recruitment of marine larvae. It is primarily characterized by 2 opposing current systems that differ markedly in temperature, which define at least 3 biogeographic provinces. The eastern side, known as the subtropical East Coast Province (Algoa Bay, South Africa, to the northern borders of the Kwazulu Natal coastline) embodies large stretches of sandy shores flanked by the southwards flowing $\sim 24^{\circ} \mathrm{C}$ Agulhas Current (Fig. 1; Griffiths et al. 2010). The western shoreline known as the cool-temperate Namaqua Province (Lüderitz, Namibia to Cape Point, South Africa) has typically more mixed rocky and sandy habitats, with the oceanic circulation in this region dominated by the northward flowing $\sim 12^{\circ} \mathrm{C}$ Benguela Current (Fig. 1; Griffiths et al. 2010) and several strong upwelling cells (Shannon 1985, Laudien at al. 2003). The south coast, known as the warm-temperate Agulhas Province (Cape Point to Algoa Bay, South Africa) encompasses a mixture of rocky shores and sandy beaches and, while still forming part of the Agulhas Current system, temperatures are on average $\sim 17^{\circ} \mathrm{C}$ (see Fig. 1; Griffiths et al. 2010). Seasonal wind driven upwelling (Shannon \& Nelson 1996) also occurs in this region. The exact spatial boundaries between biogeographic provinces are not strictly defined since there are some seasonal shifts in coastal currents. The most pronounced transition zone between biogeographic provinces is across the south-western point of Africa, the Cape of Good Hope (Cape Point; Griffiths et al. 2010).

To further our understanding of factors affecting geneflow along rocky shore habitat, we selected the Cape sea urchin Parechinus angulosus. It is the most widespread of southern African echinoids with a

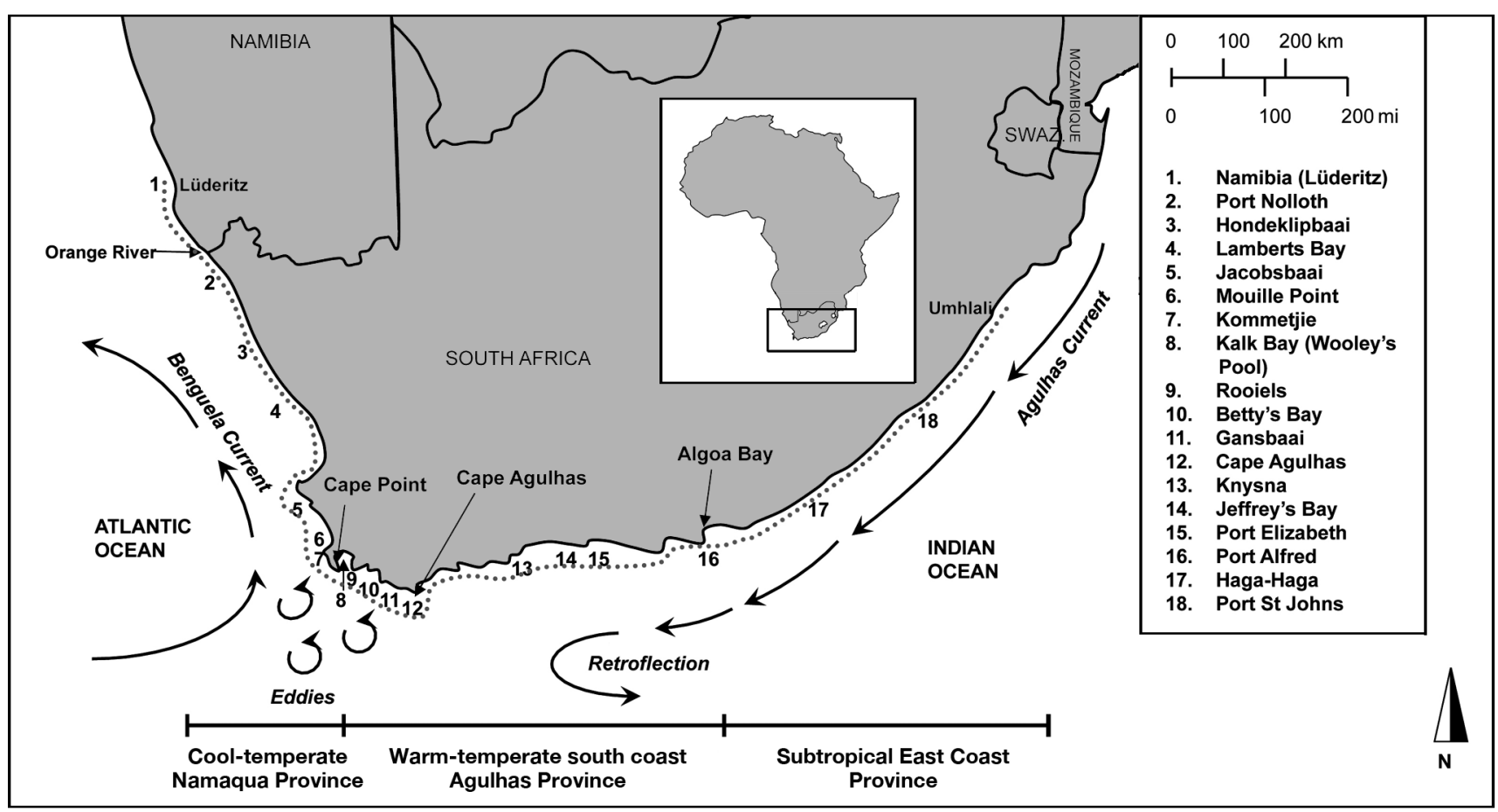

Fig. 1. Sampling localities along the southern African coastline covering the range of Parechinus angulosus (grey dotted line). Map modified after von der Heyden et al. (2008). The 3 marine biogeographic provinces and the main directions of oceanic currents are indicated. Approximate positions of the 3 known geographic barriers to dispersal (Cape Point, Cape Agulhas and Algoa Bay) are indicated by arrows 
geographical range extending from Lüderitz just north of the Orange River mouth in Namibia to Umhlali in northern Kwazulu-Natal, South Africa (Branch et al. 2002, Day \& Branch 2002; see Fig.1). Individuals of the species are found in the mid to lower zone of rocky shores and, as grazers, they play a key role in ecosystem function (Fricke 1978, 1980, Stuart \& Field 1981, Branch et al. 2002). They can form dense aggregations (Fricke 1978), reach sexual maturity at 1 to 2 yr (i.e. generation time), broadcast spawn up to 2 times per year (Greenwood 1980), and probably have a fairly long post larval development time (based on other urchin species; Lamare \& Barker 2001, Contins \& Ventura 2011). The Cape sea urchin also exhibits unique variation in colour among individuals (pink, purple and red), but there is an apparent random distribution of colour forms throughout the geographic distribution. The latter poses an additional enigmatic layer of complexity when studying the phylogeographic history of this species since evidence exists that urchin colour morphs can show assortative mating (Calderón et al. 2010).

Aside from the effect of the interplay between life history traits and biogeographic barriers on geneflow, long-term historical climatic and oceanographic change are often cited as additional factors causing marine population structuring and species diversification (e.g. Jacobs et al. 2004, González-Wevar et al. 2010, Marko et al. 2010, Teske et al. 2011). For example, Lessios et al. (2001) illustrate the importance of glaciation (changes in sea levels with associated variation in oceanic currents) in the historic distribution of sea urchins; however, a recent comprehensive review indicted that such a situation is more complex (Marco et al. 2010). In a southern African context, during glacial maxima (e.g. $22000 \mathrm{yr}$ ago), the southern coastal plain (Agulhas Bank) became exposed when sea levels dropped to $120 \mathrm{~m}$ below current levels. Glacial terminations, on the other hand, cause abrupt changes in habitat over short periods of time (Compton 2011). Associated changes in oceanic circulation during these periods also resulted in the formation of extensive coastal dune fields along the west coast Namaqua Province (Roberts et al. 2011), temporarily destroying urchin habitat. Indeed, the Agulhas Bank has been implicated as a refuge for marine intertidal organisms (von der Heyden et al. 2010), and it seems reasonable to suggest that the west and east coasts of southern Africa, where the continental shelf runs close to the shore, would provide less suitable habitat for intertidal species during times of glaciation. We hypothesize that sessile organisms such as Parechinus angulosus would be more vulnerable to sudden changes in habitat because their range shifts and extensions is mainly dependent on successful larval settlement.

The common occurrence, variation in colour forms, broadcasting mode of reproduction, along with the large distribution range of Parechinus angulosus (spanning the various unique physical attributes of the southern African coastline), makes this species a relevant candidate with which to study evolutionary biogeography in marine rocky shore invertebrates. Since assortative mating among colour morphs (see Manier \& Palumbi 2008, Calderón et al. 2010) can obscure phylogeographic interpretations, we first had to confirm that random mating occurs among the different co-occurring colour morphs at each site. Secondly, we investigated the fine-scale population structure of $P$. angulosus and hypothesised that this species would display high levels of population connectivity given its larval dispersal ability and abundance. However, based on the outcome of previous studies, it seemed reasonable to hypothesise that factors such as upwelling and biogeographic barriers in the region could also influence the pattern obtained (Avise 1992, Waters 2008, Ross et al. 2009, Kelly \& Palumbi 2010). Finally, we investigated the influence of palaeoclimatic changes on the genetic structure of the species and hypothesised that, as in previous studies of other rocky shore species (von der Heyden 2009, Marko et al. 2011, Panova et al. 2011, Teske et al. 2011), demographic change could be linked to the climatic events around the last glacial maximum. By comparing the outcome of the present study to various findings worldwide (Avise 1992, Ross et al. 2009, Kelly \& Palumbi 2010, Marko et al. 2011), it should be possible to gain a better understanding of the complex evolutionary forces influencing population connectivity in the marine realm.

\section{MATERIALS AND METHODS}

\section{Sampling protocol and gene selection}

Individual animals were collected from tidal rock pools by hand and either frozen at $-5^{\circ} \mathrm{C}$ or preserved in $100 \%$ ethanol. A total of 505 individuals were collected from 18 localities along the southern African coastline (Table 1, Fig. 1). The widely used mitochondrial cytochrome oxidase subunit I (COI; also see Bermingham \& Lessios 1993, Edmands et al. 1996, Debenham et al. 2000, Lessios et al. 2003) and a nuclear Receptor for Egg Jelly Protein 9 (SpREJ9) from the PKD1 gene family of sea urchins (Gunaratne 
Table 1. mtDNA (cytochrome c oxidase subunit I, COI) and nDNA (SpREJ9) diversity indices for the 18 sampling locations in southern Africa. n: number of urchins sampled; $h$ : haplotype diversity; $\pi$, nucleotide diversity; ${ }^{*}$ significant Fu's $F_{\mathrm{S}}$ test $(\mathrm{p}<$ 0.05); NS: not significant. Biogeographic provinces and sampling localities (1-18) depicted in Fig. 1

\begin{tabular}{|c|c|c|c|c|c|c|c|c|}
\hline \multirow{2}{*}{ Gene locality } & \multicolumn{4}{|c|}{$\operatorname{mtDNA}(\mathrm{COI})$} & \multicolumn{4}{|c|}{ - nDNA (SpREJ9) } \\
\hline & $\mathrm{n}$ & $h$ & $\pi$ & Fu's Fs & $\mathrm{n}$ & $h$ & $\pi$ & Fu's $F \mathrm{~s}$ \\
\hline \multicolumn{9}{|c|}{ Cool-temperate Namaqua Province (west coast) } \\
\hline Namibia (1) & 16 & $0.75 \pm 0.11$ & $0.0070 \pm 0.0041$ & NS & 0 & & & \\
\hline Port Nolloth (2) & 26 & $0.94 \pm 0.03$ & $0.0059 \pm 0.0033$ & $-7.3^{*}$ & 11 & $0.71 \pm 0.10$ & $0.0121 \pm 0.0077$ & NS \\
\hline Hondeklipbaai (3) & 29 & $0.84 \pm 0.05$ & $0.0033 \pm 0.0020$ & $-4.1^{*}$ & 2 & $0.83 \pm 0.22$ & $0.0054 \pm 0.0054$ & NS \\
\hline Lambertsbay (4) & 26 & $0.98 \pm 0.02$ & $0.0254 \pm 0.0110$ & NS & 3 & $0.80 \pm 0.12$ & $0.0263 \pm 0.0173$ & NS \\
\hline Jacobsbaai (5) & 26 & $0.97 \pm 0.02$ & $0.0114 \pm 0.0061$ & $-5.1^{*}$ & 9 & $0.89 \pm 0.06$ & $0.0273 \pm 0.0156$ & NS \\
\hline Mouille Point (6) & 31 & $0.92 \pm 0.03$ & $0.0136 \pm 0.0071$ & NS & 6 & $0.82 \pm 0.08$ & $0.0203 \pm 0.0124$ & NS \\
\hline Kommetjie (7) & 30 & $0.95 \pm 0.02$ & $0.0114 \pm 0.0060$ & NS & 8 & $0.88 \pm 0.06$ & $0.0230 \pm 0.0135$ & NS \\
\hline \multicolumn{9}{|c|}{ Warm-temperate Agulhas Province (south coast) } \\
\hline Wooley's Pool (8) & 28 & $0.90 \pm 0.04$ & $0.0056 \pm 0.0032$ & $-5.7^{*}$ & 9 & $0.57 \pm 0.14$ & $0.0083 \pm 0.0059$ & $-2.3^{*}$ \\
\hline Rooiels(9) & 23 & $0.90 \pm 0.05$ & $0.0090 \pm 0.0049$ & NS & 7 & $0.82 \pm 0.08$ & $0.0235 \pm 0.0139$ & NS \\
\hline Betty's Bay (10) & 45 & $0.94 \pm 0.03$ & $0.0083 \pm 0.0045$ & $-22.0^{*}$ & 25 & $0.81 \pm 0.04$ & $0.0228 \pm 0.0128$ & NS \\
\hline Gansbaai (11) & 30 & $0.96 \pm 0.02$ & $0.0058 \pm 0.0033$ & $-11.8^{*}$ & 10 & $0.81 \pm 0.07$ & $0.0259 \pm 0.0148$ & NS \\
\hline Cape Agulhas (12) & 30 & $0.92 \pm 0.04$ & $0.0044 \pm 0.0026$ & $-14.1^{*}$ & 10 & $0.79 \pm 0.09$ & $0.0270 \pm 0.0153$ & NS \\
\hline Knysna (13) & 31 & $0.89 \pm 0.05$ & $0.0043 \pm 0.0025$ & $-6.9^{*}$ & 9 & $0.84 \pm 0.07$ & $0.0274 \pm 0.0156$ & NS \\
\hline Jeffrey's Bay (14) & 20 & $0.84 \pm 0.06$ & $0.0062 \pm 0.0035$ & NS & 1 & $1.00 \pm 0.50$ & $0.0385 \pm 0.0411$ & NS \\
\hline Port Elizabeth (15) & 30 & $0.85 \pm 0.05$ & $0.0035 \pm 0.0021$ & NS & 10 & $0.89 \pm 0.05$ & $0.0310 \pm 0.0173$ & NS \\
\hline \multicolumn{9}{|c|}{ Subtropical East Coast Province (east coast) } \\
\hline Port Alfred (16) & 22 & $0.97 \pm 0.02$ & $0.0124 \pm 0.0066$ & NS & 7 & $0.81 \pm 0.09$ & $0.0232 \pm 0.0138$ & NS \\
\hline Haga-Haga (17) & 38 & $0.77 \pm 0.07$ & $0.0025 \pm 0.0016$ & $-7.0^{*}$ & 10 & $0.87 \pm 0.06$ & $0.0233 \pm 0.0135$ & NS \\
\hline Port St Johns (18) & 24 & $0.92 \pm 0.04$ & $0.0043 \pm 0.0025$ & $-4.7^{*}$ & 8 & $0.81 \pm 0.07$ & $0.0258 \pm 0.0149$ & NS \\
\hline
\end{tabular}

et al. 2007) was used. The PKD1 family of proteins is composed of large transmembrane glycoproteins that bind to smaller proteins to regulate signal transduction pathways and ion channel activities (Gunaratne et al. 2007). The subfamily of 10 SpREJ proteins is mainly composed of sperm plasma membrane proteins involved with sperm cell recognition (and potentially play a vital role in successful fertilization and the development of the fertilised egg; Gunaratne et al. 2007).

\section{Data generation}

Total genomic DNA was extracted from gonad tissue using standard protocols accompanying the DNEasy Kit (Qiagen). The mitochondrial DNA (mtDNA) COI gene was amplified and sequenced using the universal primers HCOI2198 (Folmer et al. 1994) and 16SB (Palumbi et al. 1991). The nuclear DNA (nDNA) fragment was amplified using the primers SpREJ9f and SpREJ9r (Gunaratne et al. 2007). PCR reactions were performed in $25 \mu \mathrm{l}$ volumes containing: $1 \mu \mathrm{l}$ of extracted DNA (diluted by 1:100 DNA: $\mathrm{H}_{2} \mathrm{O}$ for mtDNA amplification), $2.5 \mu \mathrm{l}$ of $10 \times$ PCR reaction buffer, $1.25 \mu \mathrm{l}$ of each respective primer $(0.1 \mu \mathrm{M}), 2.5 \mu \mathrm{l}$ dNTPs $(0.2 \mathrm{mM}), 2 \mu \mathrm{Mg}^{2+}$ (1.5 to $2.5 \mathrm{mM}$ ), $0.1 \mu \mathrm{l}$ of Super-Therm BioTaq DNA polymerase (Super-Therm) and distilled water. PCR cycling conditions were standard, and an annealing temperature of $45^{\circ} \mathrm{C}$ was used for the mtDNA and $55^{\circ} \mathrm{C}$ for the nDNA. Small aliquots of PCR product were separated and visualised via use of $1 \%$ agarose gels containing ethidium bromide. Gel purification was carried out using the Wizard SV Gel and PCR Clean-Up System (Promega). The purified products were cycle-sequenced using BigDye Terminator version 3.1 chemistry (Applied Biosystems) and analysed on an Applied Biosystems 3100 automated sequencer.

\section{Data analyses}

Sequences were edited and aligned in BioEdit version 7.0.9.0 (Hall 1999), and authenticity was confirmed by BLASTN (http://blast.ncbi.nlm.nih.gov) searches. mtDNA sequences were also translated to amino acids; no stop codons were observed. nDNA alleles were determined using the program Phase version 2.1 (Stephens et al. 2001). Haplotypes for both the mitochondrial and nuclear sequences were determined using Collapse 1.2 (Clement et al. 2000).

To determine whether random mating occurs among different colour morphs, 69 mtDNA sequen- 
ces and 86 nDNA sequences (consisting of randomly chosen individuals from each colour type sampled throughout the range) were selected for parsimony analysis in PAUP 4.0 (Swofford 2000). Searches were performed using a heuristic search and tree bisection-reconnection (TBR) branch-swopping and 10 random addition of taxa. Support for nodes were assessed using 100 bootstrap replications.

In the absence of genetic differentiation among colour morphs, all samples from all localities were treated as the same species (evolutionary unit) and in addition each of the 18 sampled localities (17 for SpREJ9) were treated separately. Standard diversity indices in the form of haplotype/allelic ( $h$, Nei \& Tajima 1981) and nucleotide ( $\pi$, Nei \& Li 1979) diversity and the number of polymorphic sites were calculated using Arlequin 3.1 (Excoffier et al. 2005). Analysis of molecular variance (AMOVA) using a non-parametric permutation approach (with 10000 iterations), as well as the calculation of pairwise $\Phi_{\mathrm{ST}}$ values among sampling sites, were conducted in Arlequin 3.1. To depict the evolutionary relationships among haplotypes, statistical parsimony networks were constructed using the program TCS version 1.21 (Clement et al. 2000).

To determine potential population structure without a priori assumptions, a Bayesian analysis of population structure (BAPS; Corander et al. 2003, 2008) was used for both the mtDNA and nDNA data sets. The latitude and longitude coordinates for each sampling location were obtained using Google Earth ${ }^{\circledR}$ and verified with MapSource ${ }^{\circledR}$ software $\left(\right.$ Garmin ${ }^{\circledR}$ ). To determine whether any potential population structure could be ascribed to geographic distance, isolation by distance (IBD) analyses was done using a Mantel test and 10000 permutations in Arlequin 3.1. To exclude the possibility that transition zones could act as barriers to geneflow and skew results obtained from a larger scale IBD analysis (e.g. Teske et al. 2007 and references therein, Teske et al. 2009) data from each biogeographic region was also analysed separately.

Migrate-n version 2.4 (Beerli \& Felsenstein 1999, 2001) was used to infer the effects of the direction of oceanic currents on long term larval dispersal. A stepping-stone model with asymmetrical geneflow was assumed (e.g. von der Heyden et al. 2008), and 2 systematic runs were conducted: an initial short run, followed by a second longer run. Population fixation index values were used as priors (Beerli \& Felsenstein 1999) and a total of 50000 and 12500000 genealogies (recorded steps multiplied by the sampling increment) were visited by the short and long chains, respectively. For both the short and long chains, the first 10000 genealogies were discarded (the burn-in). An adaptive heating scheme with 4 chains (starting values of $5.00,2.50,1.50,1.00$ ) and a swapping interval of 1 was used to ensure that efficient mixing occurred. Default values were implemented for all other settings.

To gain further insight with respect to the underlying demography of the species, Fu's $F_{\mathrm{S}}$ (Fu 1997) test was carried out in addition to mismatch distributions (Harpending 1994) as implemented in Arlequin 3.1. The time of population expansion for all sampling localities combined, as well as separately for the Namaqua, Agulhas and East Coast Provinces, was calculated with the formula $T=\tau / 2 \mu$, with $\tau$ being calculated in Arlequin 3.1. The generation time for Parechinus angulosus was set to 1.5 to $2 \mathrm{yr}$ (Greenwood 1980 ) and a mutation rate $(\mu)$ varying between 1.6 to $2.6 \%$ per million yr (Hickerson et al. 2003) was used. MDIV (Nielsen \& Wakeley 2001) was used to calculate the divergence time between the 2 most genetically divergent mtDNA groups of $P$. angulosus. Three simulations were run with $2 \times 10^{6}, 5 \times 10^{6}$, and $10 \times 10^{6}$ generations; all had a $10 \%$ burn-in and the same mutation rate was used as outlined above (Hickerson et al. 2003).

\section{RESULTS}

No clear clustering pattern emerged when either the mtDNA (COI) or the nDNA (SpREJ9) data were analysed under the prediction that differentiation could be present among colour morphs. Both parsimony trees resulted in polyphyletic associations among different colour morphs, and several nodes clustering individuals belonging to different colour forms were supported by $>90 \%$ bootstrap (data not shown). In fact, many different colour morphs shared identical DNA haplotypes/alleles further suggesting the absence of evolutionary differentiation among colour morphs.

The 505 sea urchins sequenced generated 199 mtDNA haplotypes (of $790 \mathrm{bp}$ length) of which 164 were unique and 35 shared among individuals (GenBank accession numbers KC005306 to KC005504). A large number of unique haplotypes were found, which is reflected in a high haplotype diversity index $(h=0.95 \pm$ 0.01). Most individuals, however, shared a couple of common haplotypes, which is reflected in the overall low nucleotide diversity $(\pi=0.0134 \pm 0.0067$; Table 1$)$. nDNA amplification was performed on a selection of the sample representing all 199 mtDNA haplotypes. 
The Namibian samples included in the mtDNA analyses were characterized by degraded DNA samples and failed to amplify for the nDNA. Some additional unique haplotypes also failed to amplify despite several attempts. The final nDNA data set comprised 145 individuals revealing 72 unique nDNA alleles (GenBank accession numbers KC005505 to KC005649). Due to extreme inter-individual variability in the intron region of SpREJ9, only $182 \mathrm{bp}$ of the coding part of the gene was included in the analyses. Many of the alleles (69.4\%) were restricted to single sampling sites. When compared to values obtained for the mtDNA, nuclear allelic diversity $(h=0.86 \pm$ 0.01 ) was lower and the nucleotide diversity was slightly higher $(\pi=0.0252 \pm 0.0137)$. A similar general pattern is reflected when these statistics were determined for each sampling site separately (Table 1).

Pairwise mtDNA $\Phi_{\mathrm{ST}}$ values among sampled localities indicated significant population differentiation among sampling sites (Table 2). With the exception of 3 pairwise comparisons, all the sampling sites from the Namaqua Province (localities 1 to 7 ) showed significant differentiation among sampling sites and this trend was extended to also include significant differentiation to all other populations in the other 2 biogeographic provinces (localities 1 to 7 vs. 8 to 18; Table 2). The nDNA data did not show the same level of population differentiation among sampling sites, which amongst other explanations, is most likely due to the larger effective population size of the nuclear markers and their slower coalescent times (Table 2).

A significant relationship between genetic and geographical distance was detected by the Mantel test $\left(\mathrm{R}^{2}=0.58, \mathrm{p}<\right.$ $0.05)$ but only for the mtDNA data. When each region was analysed separately, the mtDNA isolation-by-distance pattern remained significant for the Namaqua and Agulhas Provinces $\left(\mathrm{R}^{2}=0.63, \mathrm{p}<0.05\right.$ and $\mathrm{R}^{2}=0.47, \mathrm{p}<0.05$, respectively) but not for the East Coast Province.

BAPS analyses identified 2 groups within the mtDNA data set (Fig. 2): a west coast Namaqua Province group consisting of Jacobsbaai and all localities to its north,

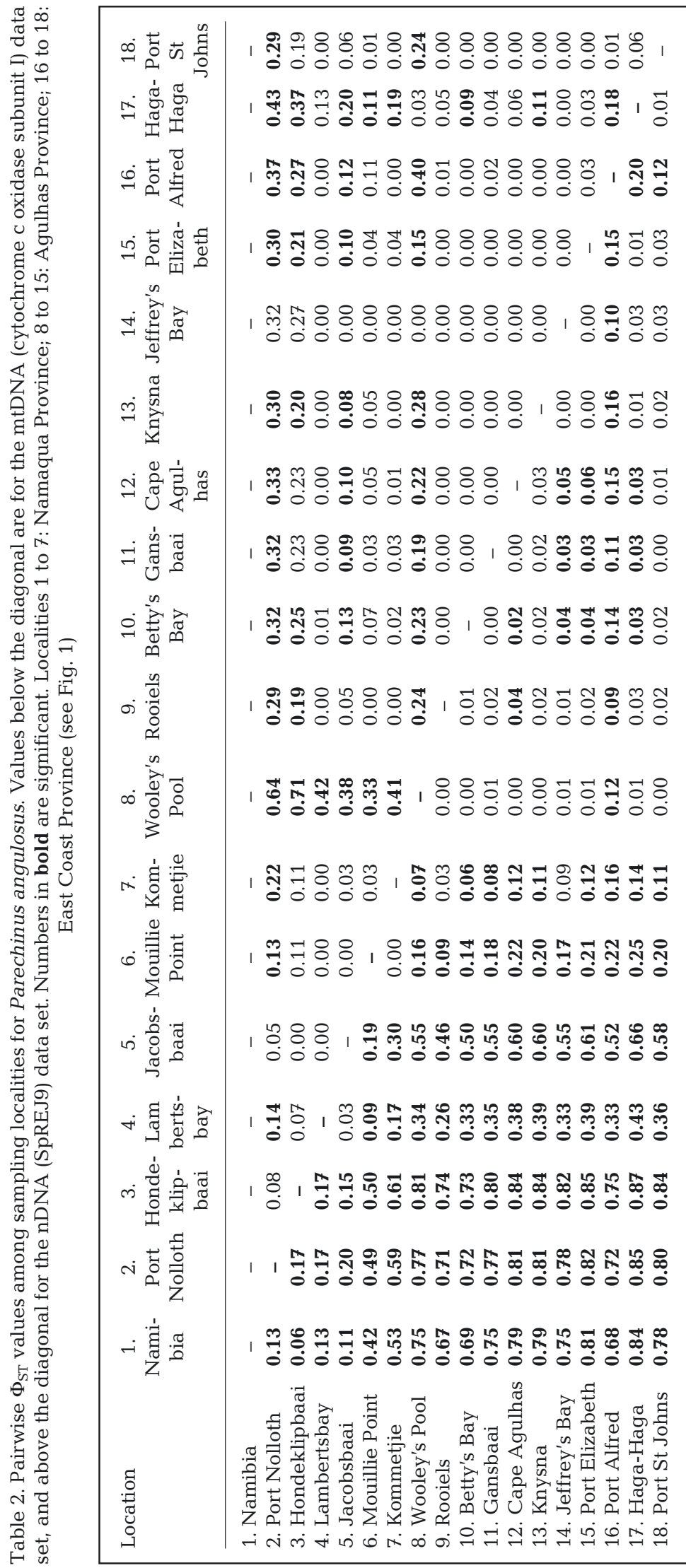


and a south coast Agulhas Province group which includes the 2 most southern Namaqua Province localities (6 and 7), as well as all the other localities up to Port St Johns in the East Coast Province. The level of certainty for this pattern was supported by a virtually flat 3 dimensional landscape (data not shown; Corander et al. 2008). In agreement with the outcome of the pairwise $\Phi_{\mathrm{ST}}$ comparisons for the nDNA data set, and the lack of isolation-by-distance for the same data, the BAPS analyses also failed to identify significant SpREJ9 group structure.

The mtDNA parsimony haplotype network revealed several distantly related common haplotypes distributed throughout the range of the species (Fig. 3a), a pattern typically attributed to a more stable evolutionary history. The number of private haplotypes at each locality ranged from 3 at Jeffrey's Bay to 26 at Betty's Bay. In addition, 10 singleton haplotypes (not statistically connected to any other haplotype) were recovered, with an additional 2 connected to one another by a single site change. These unique haplotypes mainly originate from the edges of Parechinus angulosus' range and further support the significant isolation-by-distance result obtained from the mtDNA data set. At the larger geographic scale, 1 common haplotype was present in the Namaqua Province, with 3 different common haplotypes in the Agulhas and East Coast Provinces (Fig. 3a). The majority of haplotypes found in the Namaqua Province differ by at least 14 site changes to those found along the rest of the South African coastline and the biogeographic regional differentiation between haplotypes is clearly visible when the 3 provinces are compared to each other (Fig. 3a). In contrast to all other nDNA analyses, the nuclear haplotype network shows a similar trend to that found for the mtDNA and supports the genetic differentiation between the Namaqua Province and the remainder of the sampling sites (Fig. 3b).

Interestingly, coalescent geneflow analyses of both nDNA and mtDNA revealed a predominantly bidirectional scenario of geneflow for Parechinus angulosus populations distributed along the southern African coast (Fig. 4).

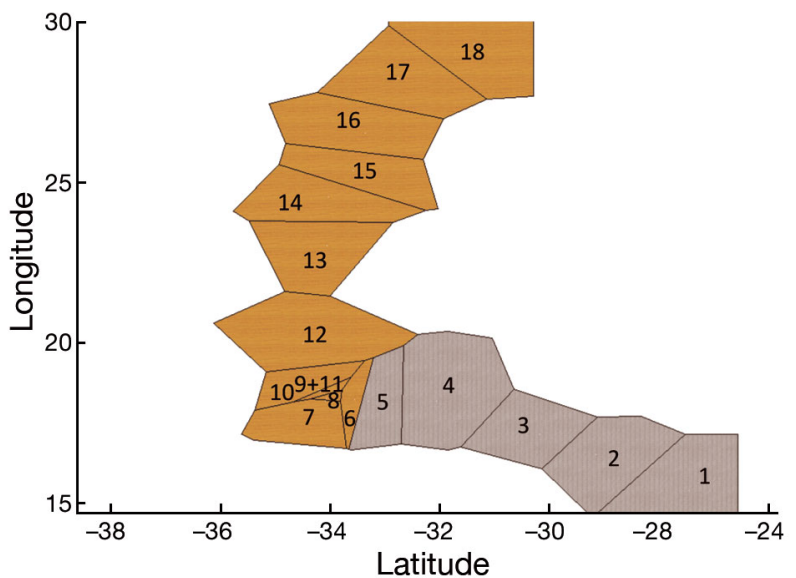

Fig. 2. Bayesian analysis of population structure (BAPS) of the cytochrome oxidase subunit Parechinus angulosus data showing the population differentiation of west coast urchins (sampling localities 1 to 5 shaded grey) and south-west, south and east coast urchins (sampling localities 6 to 18

shaded orange). Sampling areas are detailed in Fig. 1

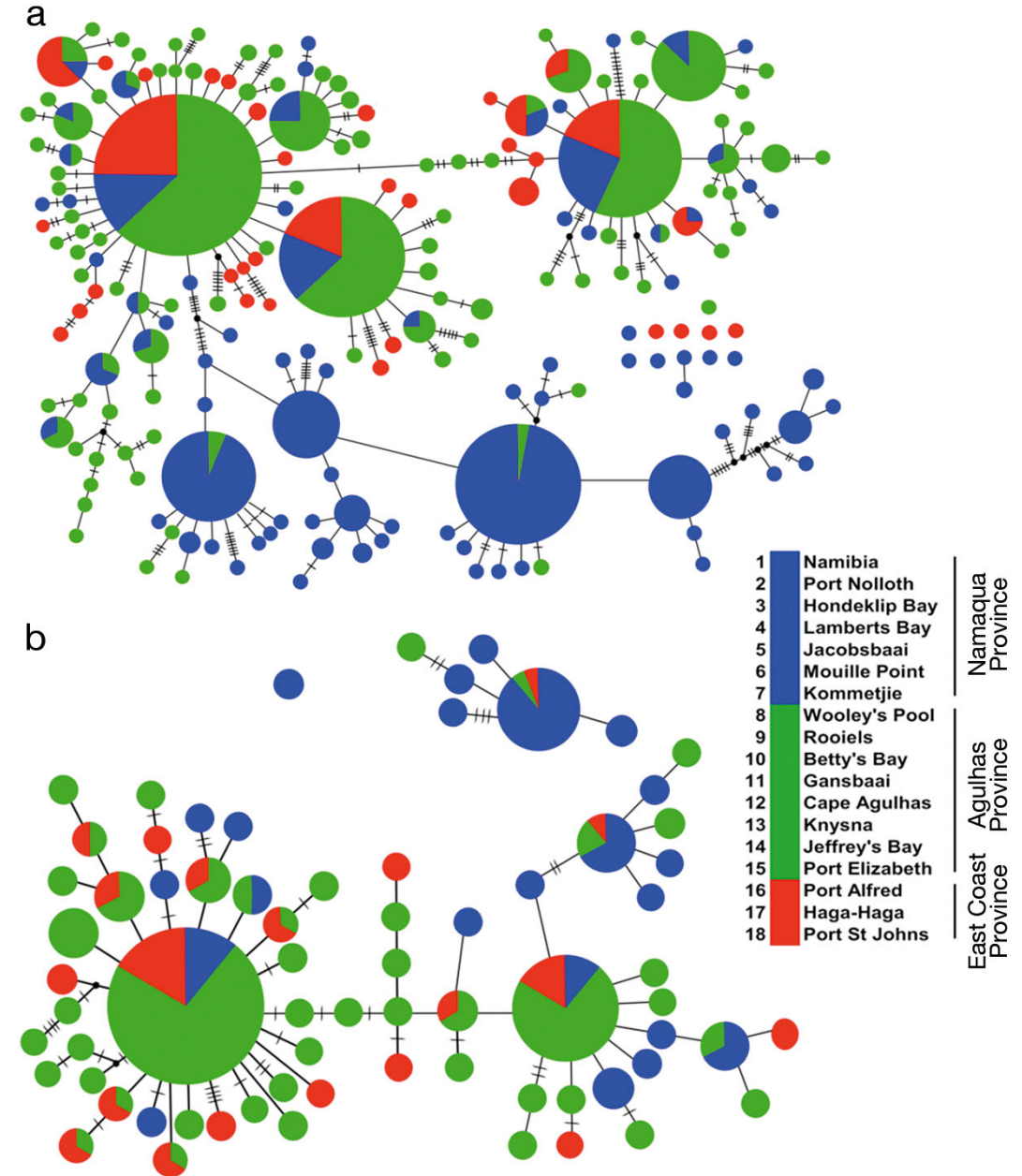

Fig. 3. (a) mtDNA and (b) nDNA parsimony haplotype networks drawn according to biogeographic provinces as listed in the inset. Size of the circles is proportional to the frequency of each haplotype; the small black dots represent unsampled or extinct haplotypes. Each cross line represents 1 mutational step 
When regional comparisons were made, the effects of oceanic circulation on the dispersal of larvae were more visible. In the Namaqua Province, geneflow appeared to be predominantly in a northward direction, following the direction of the Benguela Current, with very little migrant exchange between Namibia and Port Nolloth (Fig. 4). In the Cape Point region, there were high levels of geneflow from east (Wooley's Pool) to west (Kommetjie; Fig. 4) but interestingly much lower geneflow in the opposite direction.
Geneflow was more bidirectional in the Agulhas and East Coast Provinces (Fig. 4).

Fu's $F_{\mathrm{S}}$ test for all sites combined was highly negative and significant $(-23.79, \mathrm{p}<0.05)$ and individual analyses for some of the sampled localities also showed strong deviations from equilibrium. In most instances the mismatch distributions (data not shown) support population expansions. When analysed separately, the west coast urchins had a much later expansion date of around $4000 \mathrm{yr}$, compared to

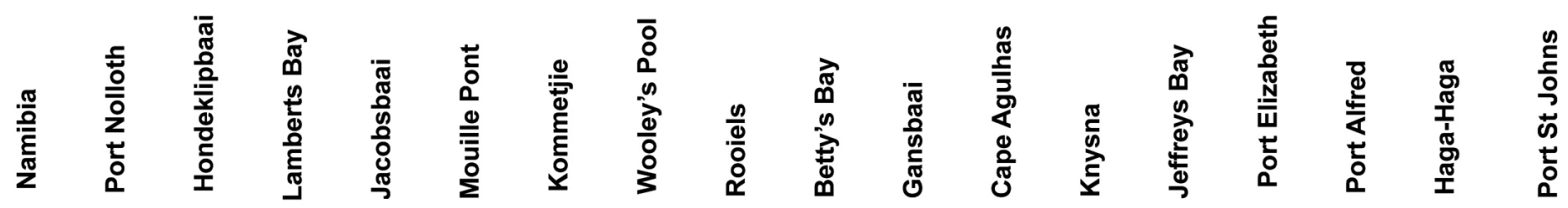

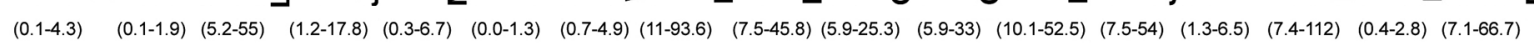
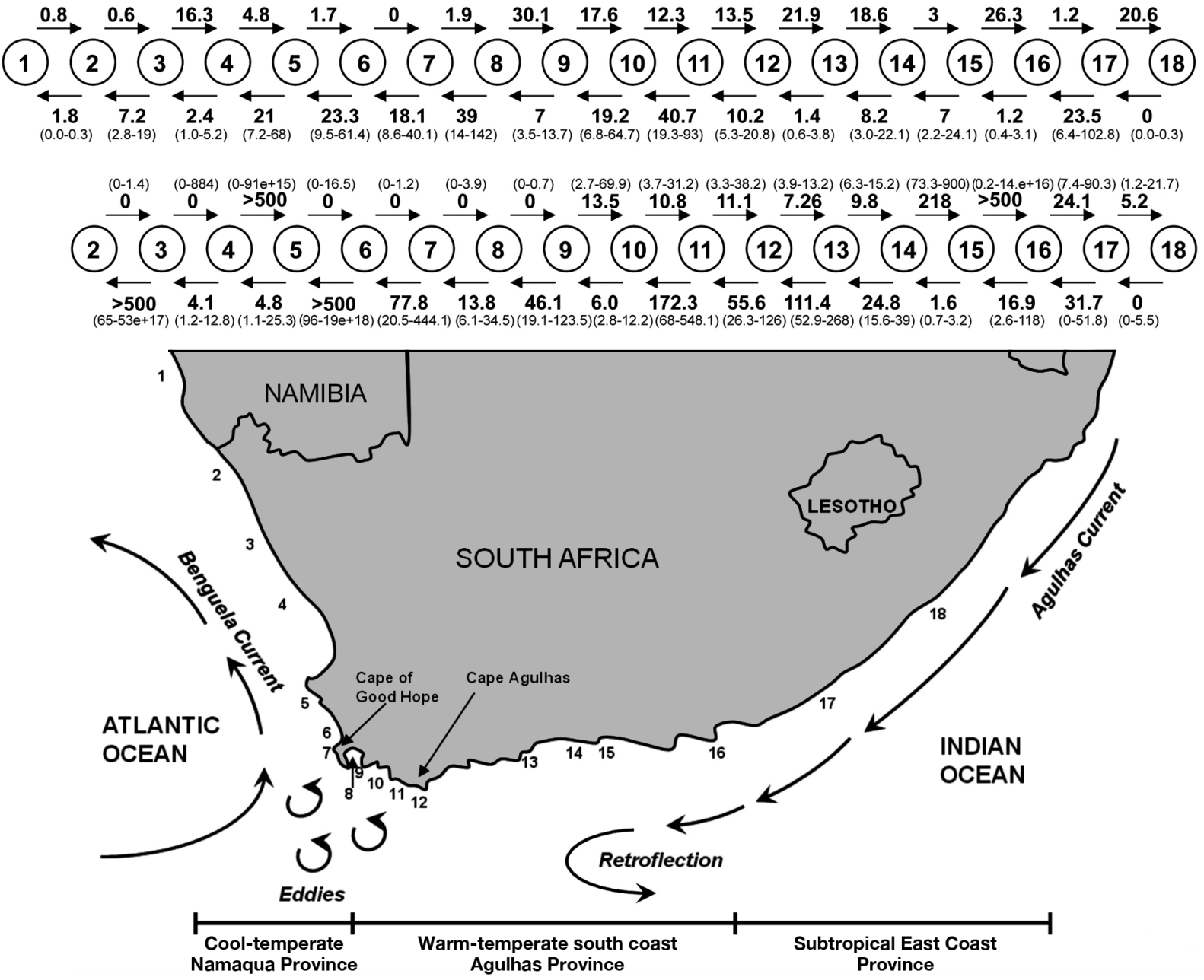

Fig. 4. Southern African coastline showing directionality of geneflow for Parechinus angulosus mtDNA (cytochrome c oxidase subunit I: sampling localities 1 to18 along the top) and nDNA (SpREJ9: sampling localities 2 to 18 below). The 3 major marine biogeographical provinces of the coast are indicated at the bottom of the figure. Directionality of geneflow is indicated between populations by arrows; numbers above and below the arrows denote the relative migration rates (with their associated confidence intervals). Map modified after von der Heyden et al. (2008) 
those from the south and east coast, for which expansion was estimated at around $3000 \mathrm{yr}$ ago. MDIV analyses suggest that individuals from the Namaqua Province became separated from the Agulhas and East Coast Province populations at least 4000 yr ago.

\section{DISCUSSION}

\section{Colour variation in the Cape urchin}

Neither the COI nor the SpREJ9 data revealed any significant phylogenetic associations among individuals belonging to the 3 different Parechinus angulosus colour forms. This lack of congruence between the genetic data and the colour morphs is in line with previous echinoid studies (Boissin et al. 2008, Vardaro 2010; but see Calderón et al. 2010, Binks et al. 2011). Since individuals of different colours are often found in the same pools, it seems reasonable to conclude that mating and fertilization between colour morphs is indiscriminate.

\section{Population genetic structure and geneflow}

Our first hypothesis tested whether population genetic structure would: (1) be comparable to that of other southern African rocky shore marine species, or (2) be significantly reduced given the presumably large effective population size of the species, broadcast spawning life-history, and potentially greater dispersal of long lived larvae. Although life-history is not always a good indicator of dispersal potential (Ayre et al. 2009, Ross et al. 2009, Sivasundar \& Palumbi 2010), it is nonetheless an important consideration in a study such as this one.

When examining broad-scale patterns found in our study, it is possible to add additional descriptive evidence that can be used to interpret the processes which may drive population level structure along the southern African coastline (see Teske et al. 2011). Our data strongly support Cape Point as a region characterized by genetic discontinuities. The complexity of factors affecting larval dispersal in the marine environment, however, makes it difficult to establish causes of vicariant breaks. Our study, nonetheless, supports the notion that the broad-scale oceanic circulation in this region has been temporally and spatially fairly stable contributing towards vicariance in the Cape Point region (Lessios et al. 1999, 2003, McCartney et al. 2000, Teske et al. 2006, von der Heyden et al. 2008, 2009). It has also been pro- posed that physiological adaptations of individuals belonging to genetic assemblages on either side of Cape Point could reinforce population genetic structuring in this region (see Teske et al. 2011 for a review). In the case of the Cape sea urchin, should some Agulhas Province larvae be successfully transported around Cape Point (see Fig. 4), temperature differences might prevent settlement, growth or reproduction, and these will in turn contribute towards genetic isolation of the west coast Parechinus angulosus populations.

Closer inspection of the geneflow analyses reveals that the Cape sea urchin data lend weak support for impediments to geneflow in the Algoa Bay region (Fig. 4 in this paper; also see von der Heyden et al. 2008). This differentiation is shallow, and factors promoting genetic divergence in this region could be localised oceanographic features such as winddriven counter currents, as well as seasonal upwelling (Goschen \& Schuman 1995, Lutjeharms et al. 2000). Interestingly, Parechinus angulosus does not seem to be affected by the genetic break identified at Cape Agulhas, which is pronounced in other South African marine species (e.g. Evans et al. 2004, Teske et al. 2006, 2007, von der Heyden et al. 2008), as geneflow appears to occur readily across this region (Neethling et al. 2008).

At the species level, the strong pattern of pairwise population differentiation, and markedly reduced geneflow estimates among several Cape sea urchin populations (Fig. 4), is unexpected in a generalist broadcast spawning species with long-lived planktonic larvae. It has, however, been previously hypothesized that, apart from oceanic circulation patterns, phylogeographic structure in the marine environment can also be the result of local upwelling, larval behaviour, recruitment stochasticity, freshwater plumes from rivers and habitat availability (e.g. Greenwood 1980, Lessios et al. 2003, Banks et al. 2007, Neethling et al. 2008, von der Heyden et al. 2008, Ross et al. 2009, Hodgson 2010). The strong differentiation among populations occurring in the rocky Namaqua Province seems to support the notion that large stretches of presumably suitable habitat do not necessarily improve geneflow among sampling sites. Self-recruitment (Cram 1971, Levin 2006, Pineda et al. 2009) and recruitment stochasticity (Greenwood 1980) are not in conflict with the patterns obtained in our study, but these are more difficult to assess. We propose that, apart from the direction of oceanic currents, the majority of the fine-scale structure seen among sampling sites is likely attributed to local upwelling cells (possibly also coupled to larval behav- 
iour; see Ross et al. 2009 and references therein), and this could be further affected by the periodic formation of extensive coastal dune fields in the region (Roberts et al. 2011). In the Namaqua Province, where several strong upwelling cells are present (Shannon 1985, Laudien et al. 2003), Parechinus angulosus shows strong population differentiation (Table 2 \& Fig. 4) while seasonal upwelling along the Agulhas Province is more wind-dependent and not as intense, providing a more permeable barrier to larval dispersal and thus less structure among sampling sites (Shannon \& Nelson 1996). Notably, for the rocky shore clinid Clinus superciliosus, significant population genetic structuring was also observed along the west coast (von der Heyden et al. 2011). This warrants further investigation into population genetic structuring of marine species found along the west coast, as this suggests the presence of fine-scale oceanographic processes driving population (and potentially species) diversification in this fragile and threatened environment.

The importance of oceanic circulation is well illustrated by the nDNA and mtDNA geneflow analyses (Fig. 4). Among the comparisons for the Namaqua populations all but one suggest a predominantly northern direction of geneflow (Fig. 4) supporting a strong uni-directional northward dispersal of larvae (in accordance with the northward flowing Benguela current). For the Agulhas and East Coast Provinces, geneflow was much more bidirectional (5 comparisons suggest east/north-east and 6 comparisons suggest a counter west/south-west direction; Fig. 4). More importantly, the mtDNA and nDNA analyses suggest very little $(<2$ migrants per population maximum; Fig. 4) to no geneflow from west to east around Cape Point (from Mouille Point to Kommetjie to Wooley's Pool, Fig. 4). This pattern was also shown for the rocky shore fish Clinus cottoides (von der Heyden et al. 2008) and may be linked to eddies associated with the Agulhas Current that mix with the northward flowing waters of the Benguela Current (Shannon 1985, Lutjeharms 2006, Reason et al. 2006). No welldocumented counter mechanisms exist in this region to facilitate gene-exchange in the opposite direction. Although upwelling in the Cape Point region cannot be ruled out as another contributing factor that reinforces the distinction of the 2 genetic clades obtained (Shannon \& Nelson 1996, Laudien et al. 2003, Lessios et al. 2003, Banks et al. 2007), we believe a strong case can be made that the flow of the Agulhas and Benguela Currents is one of the main drivers of the divergence found among Parechinus angulosus sampling sites.

\section{Paleoclimate as an agent of diversification}

Our second hypothesis focused on the influence of Pleistocene climate change, especially glacial cycles, as a factor contributing towards the diversification in this rocky shore species (also see Marko et al. 2010). The stronger structure amongst populations in the Namaqua Province could also be explained when the effects of Pleistocene climate changes are superimposed on the genetic patterns observed. The high haplotypic and low nucleotide diversity (Table 2), significant $\mathrm{Fu}^{\prime} \mathrm{F}_{S}$ values, unimodal mismatch distributions and haplotype sharing among several localities support a signature of a population bottleneck followed by a recent population expansion. Expansion estimates for the Cape sea urchin differ between localities. For the south and east coast urchins, expansion estimates suggest population growth before the last glacial maximum around 30000 yr ago, whereas for the west coast populations, this is far later, only 4000 yr ago. This is particularly interesting as it suggests that the south and east coast populations were more stable through the glaciation, which is also supported by the many older and more divergent haplotypes in the network (Fig. 3a). The Namaqua Province is characterized by only a few common haplotypes, and a number of closely related haplotypes connected to these; this pattern reflects a more recent founder event when compared to that of the Agulhas and East Coast Provinces, which has fewer unique haplotypes. Whether the reduction and subsequent expansion of populations is related to changes in the availability of habitat, or is due to temperature and other abiotic factors, is as yet unknown. However, southern African fishes, as well as crustaceans, have been found to also share recent expansion signatures similar to that observed for Parechinus angulosus (Tolley et al. 2005, Gopal et al. 2006, von der Heyden et al. 2010), and it is likely that this pattern extended into the southern Atlantic Ocean (von der Heyden et al. 2007).

The Agulhas Province populations exhibit a high number of shared haplotypes, and it is noteworthy that the Betty's Bay region was observed to be the most diverse according to number of private haplotypes/alleles (Table 1) and Jeffrey's Bay was observed to be the most diverse according to mtDNA haplotype and nucleotide diversity $(h=1.00 \pm 0.50$, $\pi=0.0385 \pm 0.0411)$. Interestingly, the Betty's Bay region is also characterized by the Hangklip and Danger point ridges that were exposed during the last glacial maximum (Compton, 2011), which makes this region ideal for providing suitable refugia to 
intertidal rock dwellers such as sea urchins (also see Matthee et al. 2007, von der Heyden et al. 2008). Importantly, during glacial maxima these ridges extended up to $70 \mathrm{~km}$ south and may have severely affected oceanic circulation in the region and thus contributed further to emphasise Cape Point as a dispersal barrier.

\section{Broader inferences on rocky shore phylogeography}

The phylogeographic pattern obtained for the sea urchin Parechinus angulosus supports the predictions that life history and biogeographic barriers are both important factors influencing larval dispersal in the marine environment (also see Sherman et al. 2008, Ross et al. 2009, Kelly \& Palumbi 2010). The present study indicated clear genetic differentiation between urchins sampled in the Namaqua Province versus the Agulhas and East Coast Provinces. The geographic position of this break corresponds very well to Cape Point, which is a major marine biogeographic boundary in South Africa (Griffiths et al. 2010, Teske et al. 2011) and lends further support to the notion that genetic discontinuities in marine species often coincide with major biogeographic boundaries (Avise 1992, Burton 1998, Kelly \& Palumbi 2010, von der Heyden et al. 2011).

Life history can also clearly play an important role in predicting geneflow among populations (Sherman et al. 2008, Ross et al. 2009, Kelly \& Palumbi 2010, Sivasundar \& Palumbi 2010), but the outcome of our study emphasises that linking life history with oceanic circulation is very complex. Despite a broadcasting mode of reproduction and probably a fairly long post larval duration time (that would suggest lower levels of genetic differentiation), the 2 Parechinus angulosus genetic assemblages show different levels of differentiation among sampling sites. The near absence of significant population differentiation among the Agulhas and East Coast Provinces, and the marked significant differentiation among populations samples in the Namaqua Province suggest that apart from life history characteristics, differences in the oceanographic circulation patterns are equally important in shaping rocky shore marine phylogeography. Along the Agulhas coast, where seasonal upwelling is predominantly wind driven (Shannon \& Nelson 1996), little genetic structure exists and this is further supported by estimations of bidirectional geneflow. Along the west coast of southern Africa, where the continental shelf is narrow, upwelling probably plays a more important role in restricting larvae to mix with neighbouring populations. In a comprehensive analysis by Ross et al. (2009), however, it was indicated that upwelling alone cannot easily be linked to population differentiation and larval behaviour could be equally important in such instances.

The effects of Pleistocene climatic changes on north-eastern Pacific rocky shore species have recently been investigated, and conclusions drawn from 14 species indicated that half of these show a pattern of long-term stability in population sizes throughout the last glacial maximum, whereas it was predicted that $36 \%$ of the species had been severely affected by these climatic changes (Marco et al. 2010). Our results, when compared to other marine studies from the region (Tolley et al. 2005, Matthee et al. 2007, von der Heyden et al. 2008, 2010), contribute towards this growing body of evidence investigating the real effects of climate change on marine biodiversity. It is induced that the lowering of sea levels generally restricts geneflow among rocky shore populations of the Namaqua Province and provides more habitat for individuals along the Agulhas Province. From a conservation perspective our findings highlight the need to further investigate fine-scale population connectivity along the southern African coastline since the complexity of the system is far from being adequately understood.

Acknowledgements. Marlene Neethling, Nina du Toit, Brad Mardon and Verna Bowie provided field assistance and Dane Kennedy provided support for some of the data analyses. The study was funded through a SeaChange South African National Research Foundation grant FA2006042100029.

\section{LITERATURE CITED}

Avise JC (1992) Molecular population structure and the biogeographic history of a regional fauna: a case history with lessons for conservation biology. Oikos 63:62-76

- Ayre DJ, Minchinton TE, Perrin C (2009) Does life-history predict past and current connectivity for rocky intertidal invertebrates across a marine biogeographic barrier? Mol Ecol 18:1887-1903

Banks SC, Piggott MP, Williamson JE, Bove U, Holbrook NJ, Beheregaray LB (2007) Oceanic variability and coastal topography shape genetic structure in a long-dispersing sea urchin. Ecology 88:3055-3064

> Beerli P, Felsenstein J (1999) Maximum likelihood estimation of a migration matrix and effective population sizes in two populations using a coalescent approach. Genetics 152:763-773

Beerli P, Felsenstein J (2001) Maximum likelihood estimation of a migration matrix and effective population sizes in $n$ populations by using a coalescent approach. Proc Natl Acad Sci USA 98:4563-4568

Bermingham E, Lessios HA (1993) Rate variation of protein 
and mitochondrial DNA evolution as revealed by sea urchins separated by the Isthmus of Panama. Proc Natl Acad Sci USA 90:2734-2738

Binks RM, Evans JP, Prince J, Kennington WJ (2011) Finescale patterns of genetic divergence within and between morphologically variable subspecies of the sea urchin Heliocidaris erythrgramma (Echinometridae). Biol J Linn Soc 103:578-592

Boissin E, Féral JP, Chenuil A (2008) Defining reproductively isolated units in a cryptic and syntopic species complex using mitochondrial and nuclear markers: the brooding brittle star, Amphipholis squamata (Ophiuroidea). Mol Ecol 17:1732-1744

Branch GM, Griffiths CL, Branch ML, Beckley LE (2002) Two oceans: a guide to the marine life of southern Africa, 5th edn. David Philip, Cape Town

Burton RS (1998) Intraspecific phylogeography across the Point Conception biogeographic boundary. Evolution 52: 734-745

> Calderón I, Ventura CRR, Turon X, Lessios HA (2010) Genetic divergence and assortative mating between colour morphs of the sea urchin Parecentrotus gaimardi. Mol Ecol 19:484-493

Clement M, Posada D, Crandall KA (2000) TCS: a computer program to estimate gene genealogies. Mol Ecol 9: 1657-1659

Compton JS (2011) Pleistocene sea-level fluctuations and human evolution on the southern coastal plain of South Africa. Quat Sci Rev 30:506-527

> Contins M, Ventura CRR (2011) Embryonic, larval, and postmetamorphic development of the sea urchin Cassidulus mitis (Echinoidea; Cassiduloida): an endemic brooding species from Rio de Janeiro, Brazil. Mar Biol 158: 2279-2288

Corander J, Waldmann P, Sillanpää MJ (2003) Bayesian analysis of genetic differentiation between populations. Genetics 163:367-374

Corander J, Siren J, Arjas E (2008) Bayesian spatial modeling of genetic population structure. Comput Stat 23:111-129

- Cram DL (1971) Life history studies on South African echinoids: Parechinus angulosus. Trans R Soc S Afr 39:321-337

> Day EG, Branch GM (2002) Influences of the sea urchin Parechinus angulosus (Leske) on the feeding behaviour and activity rhythms of juveniles of the South African abalone Haliotis midae Linn. J Exp Mar Biol Ecol 276: $1-17$

> Debenham P, Brzezinski M, Foltz K, Gaines S (2000) Genetic structure of the red sea urchin, Strongylocentrotus franciscanus. J Exp Mar Biol Ecol 253:49-62

> Edmands S, Moberg PE, Burton RS (1996) Allozyme and mitochondrial DNA evidence of population subdivision in the purple sea urchin Strongylocentrotus purpuratus. Mar Biol 126:443-450

Evans BS, Sweijd NA, Bowie RCK, Cook PA, Elliott NG (2004) Population genetic structure of the perlemoen Haliotis midae in South Africa: evidence of range expansion and founder events. Mar Ecol Prog Ser 270:163-172

Excoffier L, Laval G, Schneider S (2005) Arlequin version 3: an integrated software package for population genetic data analysis. Evol Bioinform Online 1:47-50

> Folmer O, Black M, Hoeh W, Lutz R, Vrijenhoek R (1994) DNA primers for amplification of mitochondrial cytochrome oxidase subunit I from diverse metazoan invertebrates. Mol Mar Biol Biotechnol 3:294-299

Fricke AH (1978) Kelp grazing by the common sea urchin Parechinus angulosus Leske in False Bay, Cape. S Afr J Zool 14:143-148
Fricke AH (1980) Aspects of population structure of Parechinus angulosus Leske, around the Cape Peninsula. S Afr J Zool 15:177-185

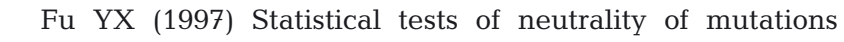
against population growth, hitchhiking and background selection. Genetics 147:915-925

> González-Wevar CA, Nakano T, Canete JI, Poulin E (2010) Molecular phylogeny and historical biogeography of Nacella (Patellogastropoda: Nacellidae) in the Southern Ocean. Mol Phylogenet Evol 56:115-124

Gopal K, Tolley KA, Groeneveld JC, Matthee CA (2006) Mitochondrial DNA variation in spiny lobster Palinurus delagoae suggests genetically structured populations in the southwestern Indian Ocean. Mar Ecol Prog Ser 319: 191-198

> Goschen WS, Schuman EH (1995) Upwelling and the occurrence of cold water around Cape Recife, Algoa Bay, South Africa. Afr J Mar Sci 16:57-67

Greenwood PJ (1980) Population dynamics and ecological energetics of Parechinus angulosus at Robben Island and False Bay, South Africa. MSc thesis, University of Cape Town, Cape Town

Griffiths CL, Robinson TB, Lange L, Mead A (2010) Marine biodiversity in South Africa: an evaluation of current states of knowledge. PLoS ONE 5: e12008

Gunaratne HJ, Moy GW, Kinukawa M, Miyata S, Mah SA, Vacquier VD (2007) The 10 sea urchin receptor for egg jelly proteins (SpREJ) are members of the polycystic kidney disease-I (PKDI) family. BMC Genomics 8:235-243

Hall TA (1999) BioEdit: a user-friendly biological sequence alignment editor and analysis program for Windows 95/98/NT. Nucl Acids Symp Ser 41:95-98

Harpending HC (1994) Signature of ancient population growth in a low-resolution mitochondrial DNA mismatch distribution. Hum Biol 66:591-600

> Hickerson MJ, Gilchrist MA, Takebayashi N (2003) Calibrating a molecular clock from phylogeographic data: moments and likelihood estimators. Evolution 57: 2216-2225

> Hodgson AN (2010) Reproductive seasonality of southern African inshore and estuarine invertebrates - a biogeographic review. Afr Zool 45:1-17

> Jacobs DK, Haney TA, Louie KD (2004) Genes, diversity and geologic process on the Pacific coast. Annu Rev Earth Planet Sci 32:601-652

Kelly RP, Palumbi SR (2010) Genetic structure among 50 species of the northeastern Pacific rocky intertidal community. PLoS ONE 5:e8594

> Lamare MD, Barker MF (2001) Settlement and recruitment of the New Zealand sea urchin Evechinus chloroticus. Mar Ecol Prog Ser 218:153-166

Largier J (2004) The importance of retention zones in the dispersal of larvae. Am Fish Soc Symp 42:105-122

> Laudien J, Flint NS, van der Bank FH, Brey T (2003) Genetic and morphological variation in four populations of the surf clam Donax serra (Roding) from southern African sandy beaches. Biochem Syst Ecol 31:751-772

> Lessios HA, Kessing BD, Robertson DR, Paulay G (1999) Phylogeography of the pantropical sea urchin Eucidaris in relation to land barriers and ocean currents. Evolution 53:806-817

Lessios HA, Kessing BD, Pearse JS (2001) Population structure and speciation in tropical seas: global phylogeography of the sea urchin Diadema. Evolution 55:955-975

Lessios HA, Kane J, Robertson DR (2003) Phylogeography of the pantropical sea urchin Tripneustes: contrasting patterns of population structure between oceans. Evolution 
57:2026-2036

Levin LA (2006) Recent progress in understanding larval dispersal: new directions and digressions. Integr Comp Biol 46:282-297

Lutjeharms JRE (2006) The ocean environment of southeastern Africa: a review. S Afr J Sci 102:419-426

> Lutjeharms JRE, Cooper J, Roberts M (2000) Upwelling at the inshore edge of the Agulhas Current. Cont Shelf Res 20:737-761

Manier MK, Palumbi SR (2008) Intraspecific divergence in sperm morphology of green sea urchin, Strongylocentrotus droebachiensis: implications for selection in broadcast spawners. BMC Evol Biol 8:283-296

- Marko PB, Hoffman JM, Emme SA, Mcgovern TM, Keever CC, Cox LN (2010) The 'Expansion-Contraction' model of Pleistocene biogeography: rocky shores suffer a sea change? Mol Ecol 19:146-169

> Matthee CA, Cockcroft AC, Gopal K, Von Der Heyden S (2007) Mitochondrial DNA variation of the west-coast rock lobster, Jasus lalandii: marked genetic diversity differences among sampling sites (2007). Mar Freshw Res 58:1130-1135

> McCartney MA, Keller G, Lessios HA (2000) Dispersal barriers in tropical oceans and speciation of Atlantic and eastern Pacific Echinometra sea urchins. Mol Ecol 9: 1391-1400

> Neethling M, Matthee CA, Bowie RCK, Von der Heyden S (2008) Evidence for panmixia despite barriers to geneflow in the southern African endemic, Caffrogobius caffer (Teleostei: Gobiidae). BMC Evol Biol 8:325-333

Nei M, Li WH (1979) Mathematical model for studying genetic variation in terms of restriction endonucleases. Proc Natl Acad Sci USA 76:5269-5273

> Nei M, Tajima F (1981) DNA polymorphism detectable by restriction endonucleases. Genetics 97:145-163

> Nielsen R, Wakeley JW (2001) Distinguishing migration from isolation: an MCMC approach. Genetics 158:885-896

Panova M, Blakeslee AMH, Miller AW, Mäkinen T and others (2011) Glacial history of the North Atlantic marine snail, Littorina saxatilis, inferred from distribution of mitochondrial DNA lineages. PLoS ONE 6:e17511

Pineda J, Reyns NB, Starczak VR (2009) Complexity and simplification in understanding recruitment in benthic populations. Popul Ecol 51:17-32

Reason CJC, Engelbrecht F, Landman WA, Lutjeharms JRE, Piketh S, de Rautenbach CJW, Hewitson BC (2006) A review of South African research in atmospheric science and physical oceanography during 200-2005. S Afr J Sci 102:35-45

Roberts DL, Matthews T, Herries AIR, Boulter C and others (2011) Regional and global palaeoenvironmental and sea level context of the Late Cenozoic Langebaanweg (LBW) palaeontological site: west coast of South Africa. Earth Sci Rev 106:191-214

Ross PM, Hogg ID, Pilditch CA, Lundquist CJ (2009) Phylogeography of New Zealand's coastal benthos. NZ J Mar Freshw Res 43:1009-1027

Shannon LV (1985) The Benguela ecosystem. Part I. Evolution of the Benguela physical features and processes. Oceanogr Mar Biol Annu Rev 23:105-182

Shannon LV, Nelson G (1996) The Benguela: large scale features and processes and system variability. In: Wefer $G$, Berger WH, Siedler G, Webb DJ (eds) The south Atlantic present and past circulation. Springer, Berlin, p 163-210 Sherman CDH, Hunt A, Ayre DJ (2008) Is life-history a bar-

Editorial responsibility: Karen Miller,

Hobart, Tasmania, Australia rier to dispersal? Contrasting patterns of genetic differentiation along an oceanographically complex coast. Biol J Linn Soc 95:106-116

> Sivasundar A, Palumbi SR (2010) Life history, ecology and the biogeography of strong genetic breaks among fifteen species of Pacific rockfish, Sebastes. Mar Biol 157: 1433-1452

Stephens M, Smith NJ, Donnelly P (2001) A new statistical method for haplotype reconstruction from population data. Am J Hum Genet 68:978-989

Stuart V, Field JG (1981) Respiration and ecological energetics of the sea urchin Parechinus angulosus. S Afr J Zool 16:91-95

Swofford DL (2000) PAUP* phylogenetic analysis using parsimony ( ${ }^{*}$ and other methods) version 4 . Sinauer Associates, Sunderland, MA

- Teske PR, McQuaid CD, Froneman PW, Barker NP (2006) Impacts of marine biogeographic boundaries on phylogeographic patterns of three South African estuarine crustaceans. Mar Ecol Prog Ser 314:283-293

Teske PR, Papadopoulos I, Zardi GI, McQuaid CD, Edkins MT, Griffiths CL, Barker NP (2007) Implications of life history for genetic structure and migration rates of southern African coastal invertebrates: planktonic, abbreviated and direct development. Mar Biol 152:697-711

Teske PR, Winker H, McQuaid CD, Barker NP (2009) A tropical/subtropical biogeographic disjunction in southeastern Africa separates two evolutionary significant units of an estuarine prawn. Mar Biol 156:1265-1275

Teske PR, von der Heyden S, McQuaid CD, Barker NP (2011) A review of marine phylogeography in southern Africa. SA J Sci 107(5/6):43-53

> Tolley KA, Groeneveld JC, Gopal K, Matthee CA (2005) Mitochondrial DNA panmixia in spiny lobster Palinurus gilchristi suggests a population expansion. Mar Ecol Prog Ser 297:225-231

Vardaro MF (2010) Genetic and anatomic relationships among three morphotypes of the echinoid Echinocrepis rostrata. Invertebr Biol 129:368-375

von der Heyden S (2009) Why do we need to integrate population genetics into South African marine protected area planning? Afr J Mar Sci 31:263-269

> von der Heyden S, Groeneveld JC, Matthee CA (2007) Long current to nowhere? Genetic connectivity of Jasus tristani populations in the southern Atlantic Ocean. Afr J Mar Sci 29:491-497

> von der Heyden S, Prochazka K, Bowie RCK (2008) Significant population structure and asymmetric geneflow patterns amidst expanding populations of Clinus cottoides (Perciformes, Clinidae): application of molecular data to marine conservation planning in South Africa. Mol Ecol $17: 4812-4826$

von der Heyden S, Lipinski MR, Matthee CA (2010) Remarkably low mtDNA control region diversity in an abundant demersal fish. Mol Phylogenet Evol 55:1183-1188

von der Heyden S, Bowie RCK, Prochazka K, Bloomer P, Crane NL, Bernardi G (2011) Phylogeographic patterns and cryptic speciation across oceanographic barriers in South African intertidal fishes. J Evol Biol 24:2505-2519

> Waters JM (2008) Marine biogeographic disjunction in temperate Australia: historical landbridge, contemporary currents, or both? Divers Distr 14:692-700

> Waters JM, Wernberg T, Connell SD, Thomsen MS and others (2010) Australia's marine biogeography revisited: Back to the future? Austral Ecol 35:988-992

Submitted: December 8, 2012; Accepted: July 25, 2012

Proofs received from author(s): October 26, 2012 